\title{
Relato das experiências vivenciadas no estágio supervisionado em geografia no ensino médio
}

\section{Report of experiences experienced in the supervised internship in geography in high school}

\author{
Ana D'Arc Ribeiro ${ }^{1}$ \\ Claúdio José Bertazzo
}

\begin{abstract}
Resumo: O presente trabalho relata as experiências obtidas a partir das observações e das práticas realizadas no âmbito do curso de Geografia da Universidade Federal de Catalão (UFCAT) em Catalão, Goiás, desenvolvido a partir da disciplina Estágio Supervisionado em Geografia (ESG) no Ensino Médio, realizado no Colégio Estadual João Netto de Campos. O objetivo deste relato foi o de compartilhar ibuir com uma reflexão acerca das teorias aprendidas na universidade bem como, pensar sobre as práticas realizadas em sala de aula. $\mathrm{O}$ estágio é uma etapa indispensável do processo de formação profissional para o discente de licenciatura. Essa etapa tem por finalidade descrever, documentar e proporcionar a reflexão sobre os resultados das atividades executadas na docência. $O$ futuro professor deve ser capacitado para o exercício da docência com atividade essencial e transformadora da realidade. Portanto o estágio é um articulador da prática-teoria-prática. A pesquisa está embasada teoricamente em (PIMENTA, 2010), (CAVALCANTI, 2007) E (BRASIL 2021).
\end{abstract}

Palavras-chave: Prática docente; Formação profissional; Engajamento Profissional.

Abstract: This paper reports the experiences obtained from the observations and practices carried out in the scope of the Geography course at the Federal University of Catalão (UFCAT) in Catalão, Goiás, developed from the subject Supervised Internship in Geography (ESG) in High School, held at Colégio Estadual João Netto de Campos. The objective of this report was to share ibuir with a reflection on the theories learned at the university, as well as to think about the practices carried out in the classroom. The internship is an indispensable step in the professional training process for undergraduate students. This step is intended to describe, document and provide reflection on the results of activities performed in teaching. The future teacher must be trained to practice teaching with an essential activity that

\footnotetext{
${ }^{1}$ Universidade Federal de Catalão (UFCAT). adarcribeiro@ hotmail.com

${ }^{2}$ Universidade Federal de Catalão (UFCAT). cbertazzo@gmail.com
}

Recebido em 23/01/2022

Aprovado em 10/02/2022

Sistema de Avaliação: Double Blind Review

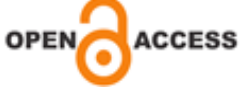




\section{REVISTA MULTIDISCIPLINAR}

ISSN 1809-1628

\section{HUMANIDADESE TECNOLOGIAS (FINOM)}

transforms reality. Therefore, the internship is an articulator of practice-theory-practice. The research is theoretically based on (PIMENTA, 2010), (CAVALCANTI, 2007) AND (BRASIL 2021).

Keywords: Teaching practice; Professional training; Professional Engagement.

\section{Introdução}

O presente trabalho relata as experiências vivenciadas a partir das observações e das práticas realizadas no curso de Geografia na Universidade Federal de Catalão (UFCAT) em Catalão, Goiás, desenvolvido a partir da disciplina Estágio Supervisionado em Geografia (ESG) no Ensino Médio, realizado no Colégio Estadual João Netto de Campos. Este relato tem como objetivo compartilhar as experiências vivenciadas durante a realização do Estágio Supervisionado em Geografia II e III, que contribuiu assim para que aja uma reflexão acerca das teorias aprendidas nas universidades bem como as práticas realizadas em sala de aula.

O estágio é uma etapa indispensável no processo de formação para o discente de licenciatura essa etapa tem por finalidade descrever, documentar e proporcionar a reflexão sobre os resultados das atividades executadas na docência. O futuro professor deve ser capacitado para o exercício da docência com atividade essencial e transformadora da realidade. Portanto o estágio é um articulador da prática-teoria-prática.

\section{Fundamentação teórica}

O ESG é o momento para se vivenciar tudo aquilo que se aprendeu durante o curso de Geografia, refletir sobre quais os recursos didáticos escolher, as formas de agir dentro da sala de aula com os alunos. Um momento de conhecer, analisar e experimentar as metodologias aprendidas teoricamente. Ao final das atividades de estágio, o licenciando deverá estar apto ao desenvolvimento de suas funções. Por sua vez, espera-se que o trabalho desse futuro profissional da Geografia possa transformar, pelo ensino, a realidade da escola e dos sujeitos nela envolvidos, com vistas à formação de cidadãos autônomos, conscientes e comprometidos com a Ciência em geral, com a Geografia em particular e com a sociedade. 


\title{
REVISTA MULTIDISCIPLINAR \\ ISSN 1809-1628 \\ HUMANIDADESE TECNOLOGIAS (FINOM)
}

Nesta perspectiva, compreende se a grande importância das atividades que são desenvolvidas dentro da sala de aula, pois levam os alunos a terem vivências com muitos assuntos que são de fundamental importância para a profissão de professor. Esse princípio está em consonância com o artigo 22 da Lei de Diretrizes e Bases da Educação, o qual dispõe que: "A educação básica tem por finalidade desenvolver o educando, assegurar-lhe a formação comum indispensável para o exercício da cidadania e fornecer-lhe meios para progredir no trabalho e em estudos posteriores" (BRASIL-LDBEN, Art. 22,1996).

Conforme Pimenta (2010) “o estágio como reflexão da práxis possibilita aos alunos que ainda não exercem o magistério aprender com aqueles que já possuem a experiência na área docente" (p. 103). Nesta Perspectiva, o estágio e o contato com a sala de aula é de fundamental importância para a formação de um novo professor. As aulas não serem presenciais, deixou o vazio da troca de experiência seria bem mais emocionante e enriquecedora.

E foi pensando em contribuir para uma aprendizagem significativa, na qual o professor tem o dever de auxiliar os alunos com o objetivo de facilitar o ensino e aprendizagem, respeitando suas individualidades durante a aula, assim o futuro profissional de educação deve propiciar a superação dessas condições propiciando aprendizagem significativa por meio do cotidiano do aluno. A sala de aula, lócus principal do estágio, proporciona um momento oportuno e insubstituível para partilha de experiências entre aluno e professor, consolidando a educação formal através do conhecimento científico. Cavalcanti (2007, p. 70), refletindo sobre a prática docente, afirma que:

\begin{abstract}
A tarefa do ensino é a de tornar os conteúdos veiculados objetos de conhecimentos para o aluno, o que requer constante diálogo do sujeito do conhecimento, portador de uma cultura determinada, com esses outros objetos culturais no sentido de atribuir-lhes significados próprios, o que é necessário para um processo de aprendizagem significativa (CAVALCANTI, 2007, p.70).
\end{abstract}

Desta forma, o processo de aprendizagem dos alunos se define e ao mesmo tempo estruturam-se pelas informações de acordo com os conhecimentos e ideias adquiridas a partir do cotidiano, em que a informação anteriormente assimilada, serve de base para que se possa estruturar uma nova. Dessa maneira, a aprendizagem significativa se realiza por meio das práticas desenvolvidas nas aulas, num momento de feliz encontro pedagógico entre o aluno e 
os conteúdos estudados, quando os alunos ancoram as novas aprendizagens e informações àquelas já internalizadas.

\section{Metodologia-desenvolvimento}

Observações da prática da professora regente

A observação foi a primeira etapa do nosso estágio, nesse momento tivemos a oportunidade de conhecer de perto a realidade de uma sala de aula, perceber os desafios que estavam por vir, bem como aprender a lidar com eles e até mesmo saber como superá-los. Conforme Libâneo (1994 p. 64) o que o professor tem a fazer é colocar o aluno em condições propícias para que, partindo das suas necessidades e estimulando os seus interesses, possa buscar por si mesmo conhecimento e experiência.

A rotina na sala de aula em uma turma do $2^{\circ}$ ano do ensino médio, a observação do estágio, iniciou ao observar a professora que traz a paixão pela Geografia ao estimular seus a alunos a se tornarem cidadãos concientes com o meio ambiente e com a sociedade. A regente faz um bom planejamento de suas aulas se mostrando confiante ao ministrar suas aulas, não demora muito para iniciar a aula, sempre buscando formas simples de explanar os conteúdos para seus alunos utilizando sempre recursos didáticos diferentes para as turmas como: aula expositivo-dialogada, mapa mental, vídeos e fotos, desenhos e tempestades de idéias, além dos links de sites relacionados à Geografia enviando sempre os textos antecipadamente para os alunos lerem e, depois, discutir sobre eles nas aulas. Sabemos que a Geografia tem muitas formas dinâmicas de expor os seus conteúdos teóricos, várias metodologias e didáticas simples, que pode ser utilizadas na sala de aula, mesmo em ensino remoto ou à distância.

\section{Práticas pedagógicas em sala de aula}

Desde o primeiro momento de discussão, planejamento e execução das aulas foram proporcionados momentos de experiências e aprendizados, que proporcionaram uma ampliação do repertórios de conhecimentos profissinais. A professora regente foi primordial para nossa formação, com sua sabedoria, carinho e conhecimento ao lidar com a insegurança, 
medo, e até mesmo a pouca experiência em estar em uma sala de aula. Depois de muito observar a rotina diária da professora regente, adotar suas práticas em nosso estágio era primordial, visto que os momentos de observações servirão de espelho para as práticas.

No primeiro momento/encontro do ESG foi definido preparar uma aula sobre o desmatamento no Bioma Cerrado. Portanto, foi planejado uma aula sobre o conceito do Bioma Cerrado. Posteriormente por meio de imagens para conhecer a formação do Bioma Cerrado e sua cartografia. Houve uma interação entre professor e alunos. O discentes fizeram perguntas sobre as razões do Cerrado ser chamado "Berço das águas". Também tiveram muito interesse em conhecer a vegetação do Cerrado.

No encontro seguinte, foi relembrado o conteúdo trabalhado na aula anterior, em que foi apresentado o Cerrado e suas características gerais. Assim, a aula iniciou com uma notícia de Jornal G1, disponível no site: https://g1.globo.com/jornal-nacional, sobre o aumento do desmatamento no Cerrado. Posteriormente comentários sobre o porquê desse aumento e as principais causas, a imagem de dois tratores municiados de um 'correntão' para derrubada da vegetação arbórea. A cena causou impacto aos alunos. Após a exposição da imagem uma aluna relatou que seu pai utiliza para arrancar o Cerrado para plantar soja, feijão. Surgiram perguntas: mas o solo não pode ser recuperado? Mas a vegetação nasce melhor e mais forte? Foi explicado que são mitos e que esse correntão prejudica a vegetação e o solo.

O Cerrado, ao ser desmatado para atender à demanda do mercado, sofre profundas alterações e desequilíbrios. A aula proporcionou aos alunos conhecer algumas causas (substituído por agropecuária, rodovias ou prédios residenciais) e algumas as consequências (efeitos climáticos e como a liberação de gás carbônico originado das queimadas que podem tanto impossibilitar a precipitação normal da chuva quanto aumentar) do desmatamento do Cerrado. Exemplificou-se como a flora perde suas características ao ser substituído por agropecuária, rodovias ou prédios residenciais.

Neste encontro foi enfatizado sobre a importância da educação socioambiental, na qual foi explicado como funciona o tripé da sustentabilidade. Foram colocados alguns pontos importantes sobre a produção de alimentos, ainda apresentadas algumas alternativas sustentáveis existentes para a produção de alimentos, por meio da agroflorestal e a produção sustentável de alimentos.

Essa aula foi uma retrospectiva de todas as aulas anteriores. Por meio de imagem de uma situação problema os alunos expuseram suas idéias sobre como solucionar os impactos 
ambientais. O que cada cidadão pode contribuir para que o Brasil não seja um grande deserto? Qual a contribuição em que o bioma Cerrado e a Amazônia para que não tenha deserto no Brasil? Foi uma aula com discussões, no qual os alunos expuseram suas idéias e soluções, alguns alunos, cujos pais são agropecuaristas se dispuseram a conversar com os pais sobre as agroflorestas. Outros vão começar a fazer hortas caseiras. A metodologia usada nessa aula foi assertiva, os objetivos propostos no planejamento foram alcançados de acordo com a BNCC no qual tornar os alunos cidadãos comprometidos com a sociedade.

\section{Resultados e discussões}

O planejamento das aulas possibilita o docente estabelecer um encadeamento lógico entre os assuntos ministrados, estabelecendo um cronograma específico da disciplina, propiciando o planejamento dos alunos quanto ao estudo dos assuntos. Além disso, pode permitir ao docente avaliar o desenvolvimento do próprio trabalho em sala de aula, repensando sobre o aprendizado dos alunos.

Um ponto positivo é a proposta de ensino da professora percebido na observação do ESG II, que favorece cada planejamento das aulas, trabalhar com assuntos que estão diretamente ligados à educação e ao cotidiano dos alunos, proporcionando-lhes uma aprendizagem significativa, e permitir-lhes formar pensamento crítico por meio do diálogo, sobre esse processo Freire (1997) ressalta:

O diálogo não apenas em torno dos conteúdos a serem ensinados, mas sobre a vida mesma, se verdadeiro, não somente é válido do ponto de vista do ato de ensinar, mas formador também de um clima aberto e livre no ambiente de sua classe (FREIRE, 1997, p. 59).

O diálogo sobre a rotina diária dos alunos sempre aconteceu na sala de aula. As preocupações como eles estão nesse momento de pandemia, mesmo porque são jovens e sobrem com as ansiedades de suas condições familiares e da sua comunidade. Durante as observações percebe-se como a professora Silêda dialoga com os alunos como grandes amigos, isso deixa os alunos bem a vontade durante a aula.

A experiência de convicência nas classes prorciona ao estagiário perceber a importância de se formar um profissional qualificado, com domínio de conteúdo, e capaz de trabalhar com as diferenças existentes no meio de trabalho, seja este uma sala de aula, uma 
escola como um todo, ou mesmo a sociedade de forma geral. A contribuição de vários profissionais da educação durante as três etapas anteriores do Estágio Supervisionado foram fundamentais, porque possibilitou perceber a criatividade e a simplicidade com a qual planejam suas aulas e no final o resultado, sendo gratificante.

\section{Considerações finais}

Os estágios são sempre importantíssimos para a formação de um futuro professor, pois na medida em que os alunos entram nas atividades práticas são capacitados a lidar diretamente com os problemas que terá que vivenciar quando for professor e responsável por uma sala de aula, regendo sua classe. O Estágio Supervisionado é insubstituível, pois, demonstrar ao futuro professor verdadeira identidade de sua profissão. Por meio do ESG o graduando avalia sual real sua vocação enquanto educador, pois é neste momento que ele irá descobrir se realmente é essa profissão que quer seguir ou se estava equivocado quando fez a opção pela Licenciatura em Geografia.

Assim essa experiência permitirá que se tornem professores somente aqueles estagiários que queiram abraçar a profissão de mestre, permitindo que entrem no mercado apenas aqueles professores que tenham prazer em ensinar seus alunos e mediar situações de aprendizagem. Portanto as experiências obtidas no estágio foram positivas, além de ter proporcionado um novo encontro com a profissão escolhida, ainda preparar profissionalmente para enfrentarmos os futuros desafios que surgem no espaço escolar e na conjuntura educacional da sociedade.

A experiência vivida com o Estágio Supervisionado em Geografia III me fez perceber a importância da qualidade profissional, de acordo com Demo (2012) que diz "A Educação é o suporte essencial, porque forma e intrumenta a pessoa com habilidade crucial de manejar a arma mais potente de combate que é o conhecimento". Muitas perspectivas devem ser analisadas quando a formação de um professor e levada em consideração se está sendo levada a sério. Podemos concluir com isto, que o Estágio Supervisionado funciona como uma forma de inclusão dos estudantes universitários à realidade e vivência de uma escola. Visto que esse contato é de fundamental importância para a formação do novo professor que está sendo formado. 


\section{Referências}

BRASIL. Ministério da Educação. Base Nacional Comum Curricular ensino médio. Brasília, 2021. Disponível em :http://basenacionalcomum.mec.gov.br/images/historico/BNCC_EnsinoMedio. Acessado em 05 de julho de 2021.

BRASIL. Lei de Diretrizes e Bases da Educação. Lei n ${ }^{\circ} 9.394 / 96$ de 20 de dezembro de 1996. Disponível em: Acessado em 26 de julho 2010.

CAVALCANTI, L. de S. Ensino de Geografia e diversidade: construção de conhecimentos Geográficos escolares e atribuição de significados pelos diversos sujeitos do processo de ensino. In: CASTELLAR, S. M. V. (org.). Educação Geográfica: teorias e práticas docentes. 2. ed. São Paulo: Contexto, 2007.

DEMO, P. Educação e qualidade. 12 ed. Campinas, SP; Papirus, 2012.

LIBÂNEO, José Carlos. Didática. São Paulo: Cortez, 1994.

FREIRE, P. Pedagogia da Autonomia: saberes necessários à prática educativa. 25 ed. São Paulo: Paz e Terra, 1996.

PIMENTA, S. G. Porque o estágio para quem já exerce o magistério: uma proposta de formação contínua. São Paulo: Cortêz, $5^{\circ}$ ed. 2010. 